\title{
Studies of adrenocortical function in continuous asthma
}

\author{
A. O. ROBSON AND J.R.KILBORN \\ From the Department of Medicine, Royal Victoria Infirmary, Newcastle upon Tyne, \\ and the Department of Clinical Biochemistry, University of Newcastle upon Tyne
}

Asthma has been defined (Ciba Guest Symposium, 1959) as a condition with widespread narrowing of the bronchial airways, which changes its severity over short periods of time either spontaneously or under treatment. The clinical features are abnormal breathlesness, which may be paroxysmal or persistent, wheezing, and in most cases relief by bronchodilator drugs, including corticosteroids. This definition describes a disorder of function which may be measured by any simple test of airways obstruction (Scadding, 1963).

Asthmatics may be divided into two groups depending on whether the narrowing of the airways is intermittent or continuous. Intermittent asthma is characterized by recurrent attacks of bronchospasm with periods of remission when there is no clinical evidence of asthma and ventilatory tests are normal. In continuous asthma, there is a continuously or intermittently audible wheeze, usually with breathlessness on exertion, and invariably there is evidence of expiratory obstruction on ventilatory testing. While the dyspnoea and wheezing may vary considerably and at times may not be noticed by the patient, the two groups can usually be distinguished by a careful history, and a ventilatory defect will persist despite the absence of symptoms (Engström, Escardo, Karlberg, and Kraepelin, 1959 ; Strang, 1961).

The classification of asthma as 'intermittent' and 'continuous' is based on clinical observation and implies no aetiological significance in itself, but Ogilvie (1962) has shown that, in terms of clinical course and prognosis, this classification accords closely with the aetiological classification of 'extrinsic' and 'intrinsic' asthma.

Extrinsic asthma is thought to follow exposure to an inhalant or some other allergen to which the patient is specifically sensitive. Since many asthmatics do not fall into this group, they have been called the 'mixed, unidentified, and bacterial' or intrinsic group by Rackemann and Edwards (1952). Rackemann (1958) followed 272 patients with intrinsic asthma for a long period: usually infection was the major factor in the initiation and continuation of symptoms, but it was not the only cause since many other factors seemed to be involved. Fifty-nine of his patients became 'cleared' of asthma (21.7\%), but six of these relapsed, and in his view these six patients (and, by implication, the 213 whose symptoms did not regress completely) 'show that a basic mechanism of some kind is still operative'. The idea of a basic mechanism is borne in upon anyone concerned with asthmatic patients, and it is possible that this mechanism could be endocrine in nature. This possibility is reinforced by the favourable response to corticosteroid treatment seen in the majority of asthmatic patients, although it must be recognized that some patients fail to respond to corticosteroid hormones; similarly, some respond to corticotrophin whereas others seem resistant. While infection and emotional influences may account for unexpected and refractory behaviour in many asthmatics, the continuation of symptoms can be seen in the absence of such factors.

We have tried to find out if the adrenal cortex is fundamentally concerned in continuous asthma. This is not a new concept, but most other workers have estimated the urinary and, occasionally, plasma steroids, and no consistent abnormality has been demonstrated. In recent years methods of investigation have been developed for the specific assay of plasma cortisol itself and for the measurement of actual cortisol production rates. In the present investigation these techniques have been applied to the study of adrenocortical function in continuous asthmatics and they will give a more accurate assessment of the functional state of the adrenal cortex than could be obtained by the earlier methods.

\section{SUBJECTS}

Patients were accepted for the investigation if they had continuous asthma as described previously. All 
had moderately severe asthma: although none was completely disabled, they were all liable to recurrent exacerbations of wheezing, and during intervals between acute attacks their symptoms were sufficiently disabling to interfere with their normal life. Inevitably some of the patients had some degree of chronic bronchitis, but in none was this the major disability, and no patient was tested when in an acute exacerbation or status asthmaticus. In no case had steroid therapy been given before the investigation.

Thirty-four patients were investigated, 19 males and 15 females. Their ages and the duration of symptoms are shown in Tables I and II; there was no direct relation between the ages of the patients and the duration of their symptoms. In 21 patients there was a family history of allergic disease.

T A B L E I

AGE DISTRIBUTION

\begin{tabular}{c|c}
$\begin{array}{c}\text { Age } \\
\text { (Yr.) }\end{array}$ & $\begin{array}{c}\text { No. of } \\
\text { Patients }\end{array}$ \\
\hline $0-10$ & 1 \\
$11-20$ & 7 \\
$21-30$ & 8 \\
$31-40$ & 3 \\
$41-50$ & 8 \\
$51-60$ & 7 \\
\hline
\end{tabular}

T ABLE I I

DISTRIBUTION AND DURATION OF ASTHMA

\begin{tabular}{c|c}
$\begin{array}{c}\text { Duration } \\
\text { of Asthma } \\
\text { (Yr.) }\end{array}$ & $\begin{array}{c}\text { No. of } \\
\text { Patients }\end{array}$ \\
\hline 1 & 2 \\
$1-5$ & 6 \\
$6-10$ & 9 \\
$11-20$ & 10 \\
$21-40$ & 6 \\
40 & 1 \\
\hline
\end{tabular}

\section{METHODS}

The investigations were designed to measure the rate at which cortisol is produced in the resting state and the extent to which the adrenal cortex is capable of responding to stimulation with adrenocorticotrophic hormone (A.C.T.H.).

RESPONSE OF PLASMA CORTISOL TO A.C.T.H. STIMULATION The infusion was started at 09.30 hours, using 30 units of corticotrophin (Cortrophin, Organon) in $500 \mathrm{ml}$. of normal saline. The corticotrophin was obtained as a lypholized powder and stored in deep freeze until required. The infusion was regulated to deliver at least 25 units of corticotrophin in eight hours. Blood samples were obtained before the start of the infusion, at two-hourly intervals during the infusion, and at 09.30 hours the following day.

ASSAY OF PLASMA CORTISOL Plasma cortisol was assayed by a modification (Cameron and Kilborn,
1964) of the method of Stewart, Albert-Recht, and Osman (1961). Plasma, $1 \mathrm{ml}$., was mixed with $1 \mathrm{ml}$. $\mathrm{N} / 20 \mathrm{NaOH}$ after being washed with petroleum ether for de-fatting, and was extracted twice with $12 \mathrm{ml}$. dichloromethane. The extracts were evaporated to dryness under reduced pressure below $40^{\circ} \mathrm{C}$., and $0.4 \mathrm{ml}$. absolute ethanol was added to the residue. Two minutes after the addition of $3.6 \mathrm{ml}$. of a $75 / 25$ (v/v) sulphuric acid/water reagent the fluorescence was measured at $520 \mu$ on excitation at $480 \mu$ and the rise from a low level at $2 \mathrm{~min}$. to a high steady value at $120 \mathrm{~min}$. was followed. The amount of fluorescence due to cortisol, corticosterone, and interfering substances was then calculated by the method of Stewart et al. (1961).

CORTISOL PRODUCTION RATE Cortisol production rates were measured by an isotope dilution method depending on the specific activity of a urinary metabolite, using De Witt, Robson, and Stewart's (1962) modification of the method of Cope and Black (1958).

Cortisol-4-14 $\mathrm{C}$ of high specific activity $(42 \cdot 4 \mu \mathrm{c}$. per mg.), $0.5 \mu \mathrm{c}$., was given by mouth at 09.00 hours on the first morning. Two consecutive 24-hour urine collections were made. Part of the first collection was hydrolysed with beta-glucuronidase and extracted with chloroform, and tetrahydrocortisone was isolated from the extract by paper chromatography. The tetrahydrocortisone was eluted from the paper, and its specific activity was found by assaying it by the blue tetrazolium reaction and measuring its radioactivity in a liquid scintillation counter. The total radioactivity of the 24-hour collection was determined under the same conditions, and cortisol production rates were calculated according to the expression :

\section{Total radioactivity of the 24-hour urine Specific activity of tetrahydrocortisone}

This method measures the total mass of the metabolites derived from cortisol alone and is regarded as the most satisfactory guide to cortisol secretion at present available.

The second 24-hour urine collection was made to check that the excretion of ${ }^{14} \mathrm{C}$ was complete.

\section{RESULTS}

RESPONSE TO STIMULATION BY A.C.T.H. The mean plasma cortisol figures obtained for the 34 subjects are shown in Fig. 1, and a statistical analysis of the results is given in Table III.

These results have been compared with those obtained by one of us (Cameron and Kilborn, 1964) in 16 normal subjects, whose ages ranged from 22 years to 66 years. The subjects showed a steady rise in plasma cortisol levels to a minimum eight-hour level of $48.5 \mu \mathrm{g} . / 100 \mathrm{ml}$., with one exception; this subject only achieved an eighthour level of $30.8 \mu \mathrm{g}$. $/ 100 \mathrm{ml}$. The remainder of 
TABLE III

MEAN PLASMA CORTISOL LEVELS, STANDARD DEVIATIONS, AND STANDARD ERRORS OF THE MEANS IN 34 ASTHMATIC SUBJECTS COMPARED WITH 16 NORMAL SUBJECTS (CAMERON AND KILBORN, 1964) DURING STIMULATION WITH CORTICOTROPHIN

\begin{tabular}{|c|c|c|c|c|c|c|}
\hline & \multicolumn{6}{|c|}{ Hours After the Start of A.C.T.H. Stimulaticn } \\
\hline & 0 & 2 & 4 & 6 & 8 & 24 \\
\hline $\begin{array}{l}16 \text { normalsubjects } \\
\text { Mean ( } \mu \mathrm{g} . ! \\
100 \mathrm{ml} .) \\
\text { S.D. }\end{array}$ & $\begin{array}{c}13.0 \\
\pm 4.41 \\
\pm 1.10\end{array}$ & $\begin{array}{c}32.9 \\
\pm 7.9 \\
\pm 1.99\end{array}$ & $\begin{array}{c}39.2 \\
\pm 9.42 \\
\pm 2.35\end{array}$ & $\begin{array}{c}47 \cdot 4 \\
\pm 8 \cdot 07 \\
\pm 2.02\end{array}$ & $\begin{array}{c}53.3 \\
\pm 8.15 \\
\pm 2.04\end{array}$ & $\begin{array}{l}16 \cdot 1 \\
\pm 5 \cdot 14 \\
\pm 1.43 \\
(13)^{1}\end{array}$ \\
\hline $\begin{array}{l}34 \text { asthmatics } \\
\text { Mean ( } \mu \mathrm{g} . / \\
100 \text { ml.) } \\
\text { S.D. } \\
\text { S.E.(M.) }\end{array}$ & $\begin{array}{l}15 \cdot 4 \\
\pm 6 \cdot 20 \\
\pm 1 \cdot 08 \\
(33)^{1}\end{array}$ & $\begin{array}{l}27 \cdot 4 \\
\pm 8 \cdot 06 \\
\pm 1.43 \\
(32)^{1}\end{array}$ & $\begin{array}{c}30.5 \\
\pm 10.6 \\
\pm 1.82\end{array}$ & $\begin{array}{l}34 \cdot 7 \\
\pm 10 \cdot 2 \\
\pm 1 \cdot 84 \\
(31)^{1}\end{array}$ & $\begin{array}{c}37 \cdot 1 \\
\pm 14 \cdot 0 \\
\pm 2 \cdot 40\end{array}$ & $\begin{array}{l}11 \cdot 1 \\
\pm 6 \cdot 15 \\
\pm 1 \cdot 13 \\
(27)^{1}\end{array}$ \\
\hline
\end{tabular}

1 No. of observations.

$95 \%$ confidence for lower limit of normal at 8 hours $=4 \mathrm{C} \cdot \mathrm{C} \mu \mathrm{g}$. $100 \mathrm{ml}$.

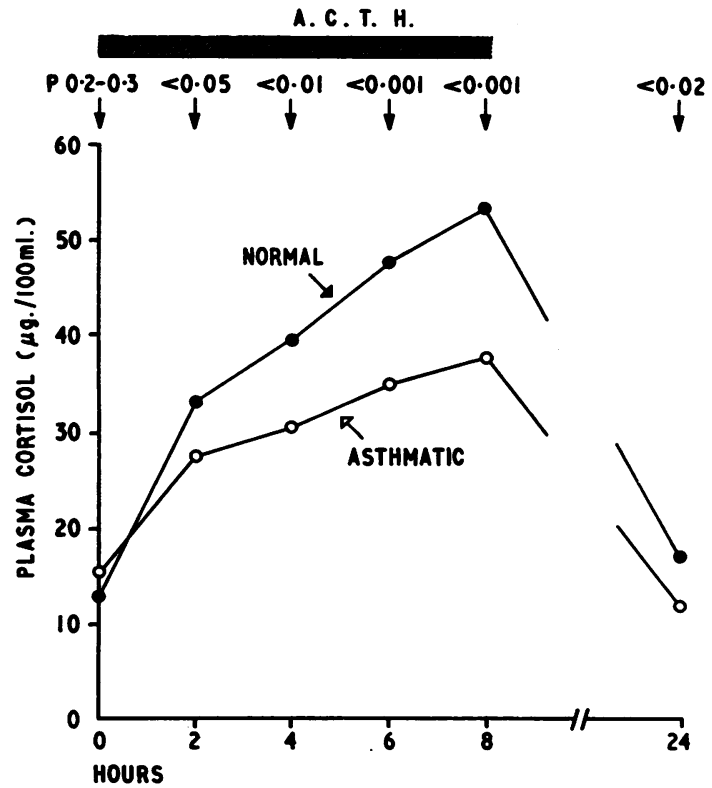

FIG. 1. Mean plasma cortisol levels during A.C.T.H. stimulation from 34 asthmatic subjects, compared with normal subjects.

the results were within a narrow range and were comparable with the results obtained by other workers using different techniques (Eik-Nes, Sandberg, Nelson, Tyler, and Samuels, 1954 ; de Moor, de Backer, Hendrikx, Hinnekens, and de Bock, 1960).

In the present series the mean basal level $(15.4 \mu \mathrm{g} . / 100 \mathrm{ml}$.) did not differ significantly from the normal $(13.0 \mu \mathrm{g} . / 100 \mathrm{ml}$.) and was in close accord with the mean level of $14.7 \mu \mathrm{g} . / 100 \mathrm{ml}$. found by Mattingly (1963) in 100 adult hospital patients. Both the asthmatic patients and the control subjects were in a resting state, and the test was started at a constant time to minimize the effect of extrinsic influences and the adrenal diurnal rhythm on the results.

It is clear (Fig. 1) that while the basal level is not significantly different from the normal the average 'asthmatic' curve during A.C.T.H. infusion is lower than that obtained in normal subjects, the difference being pronounced at six hours $(P<0.001)$ and becoming even greater at eight hours. The mean level 24 hours after starting the infusion (16 hours after stopping stimulation) was considerably lower $(P=0.01-0.02)$ than that obtained in normal subjects.

Not all the asthmatic patients showed results below the normal range. Normality has been taken as the plasma cortisol level at eight hours. This was because 15 of the 16 normal subjects showed a steady increase in the plasma cortisol levels, reaching a maximum at eight hours when stimulation ceased. The $95 \%$ confidence figure for the lower limit of normal at eight hours is $40.0 \mu \mathrm{g} . / 100 \mathrm{ml}$. (Table III). By this criterion, 23 of 34 asthmatic patients had a diminished response to A.C.T.H. stimulation. A contingency table (Table IV) shows that there is a highly significant degree of separation $(P<0.0005)$ between the results obtained from normal and from asthmatic subjects at eight hours.

T A B L E IV

CONTINGENCY TABLE FOR ASTHMATICS AND NORMAL SUBJECTS

\begin{tabular}{|c|c|c|}
\hline Status & Asthmatics & Controls \\
\hline $\begin{array}{l}\text { Diminished response } \\
\text { Normal response }\end{array}$ & $\begin{array}{l}23 \\
11\end{array}$ & $\begin{array}{r}1 \\
15\end{array}$ \\
\hline Total & 34 & 16 \\
\hline
\end{tabular}

Of the 11 asthmatic subjects regarded as having a normal response, three had eight-hour levels marginally above the lower limit of normal $(40 \cdot 4$, 41.0 , and $41.8 \mu \mathrm{g} . / 100 \mathrm{ml}$.), two had eight-hour results of $46 \cdot 3$ and $47 \cdot 1 \mu \mathrm{g} . / 100 \mathrm{ml}$. respectively, and in the remaining six the eight-hour figure exceeded $50.0 \mu \mathrm{g} . / 100 \mathrm{ml}$.

In five of the 23 patients with a diminished response at eight hours, the six-hour level was above the lower limit of normal $(34.0 \mu \mathrm{g} . / 100$ $\mathrm{ml}$.), but in each case the plasma cortisol level had fallen at eight hours, showing that these patients did not maintain a high level of secretion despite continued stimulation. 
Included in the asthmatic series are the results from seven patients under 16 years; five show a diminished response and two are within the normal adult. range. No comparable normal figures are available for this age group as we thought it was unjustified to subject normal children to an intravenous infusion for this purpose.

Interpretation of individual 24-hour levels is difficult in view of the wide variation in basal plasma cortisol levels.

CORTISOL PRODUCTION RATES The cortisol production rates have been measured in 16 adult asthmatic subjects whose ages ranged from 18 to 59 years. The results of these estimations give a mean figure of $12.1 \mathrm{mg} . / 24$ hours (S.D. $\pm 4 \cdot 1$ ). This is close to the normal mean quoted by other workers using the same technique $(13.3 \pm 3.0 \mathrm{mg}$. / 24 hours (de Witt et al., 1962); $10 \cdot 8 \pm 2 \cdot 25$ mg./24 hours (Cope and Black, 1958)).

Results from both sexes have been analysed and there is no significant difference between the two groups (mean values: males, $11.9 \mathrm{mg}$. $/ 24$ hours ; females, $13.0 \mathrm{mg} . / 24$ hours). They have therefore been included as a single group.

Production rates were measured in five asthmatics under 16 years of age, and the mean value for these subjects is $10.6 \mathrm{mg}$. $/ 24$ hours.

CLINICAL CORRELATION The clinical details of each patient were examined with special reference to age, duration of symptoms, and a family history of allergic disease.

Figure 2 is a scatter diagram of the duration of symptoms plotted against eight-hour plasma cortisol levels. There is a significant correlation between the two parameters $(y=42 \cdot 1-0.360 x$; $r=-0.360 ; P<0.05)$. No such correlation can be demonstrated (Fig. 3) when the age of the patient is compared with the response to stimulation $(\mathrm{r}=0.0046 ; \mathrm{P}>0.8)$. The association between the duration of symptoms and the eight-hour plasma cortisol level is not affected by age, since by partial correlation analysis the correlation coefficient remains unchanged $(r=-0.364)$ when age is held constant.

A family history of allergic disease had no influence on the response obtained $\left(\chi^{2}=0.0485\right.$; $\mathbf{P}>0.8)$.

\section{DISCUSSION}

Previous work in this field has been confined to the estimation of urinary steroid metabolites and,

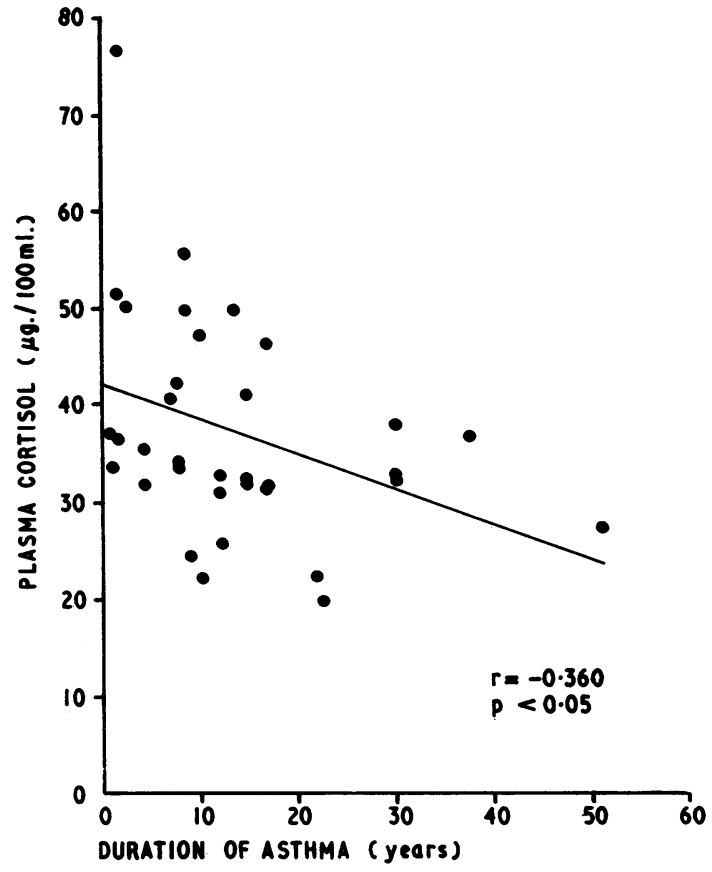

FIG. 2. Eight-hour plasma cortisol levels compared with duration of symptoms.

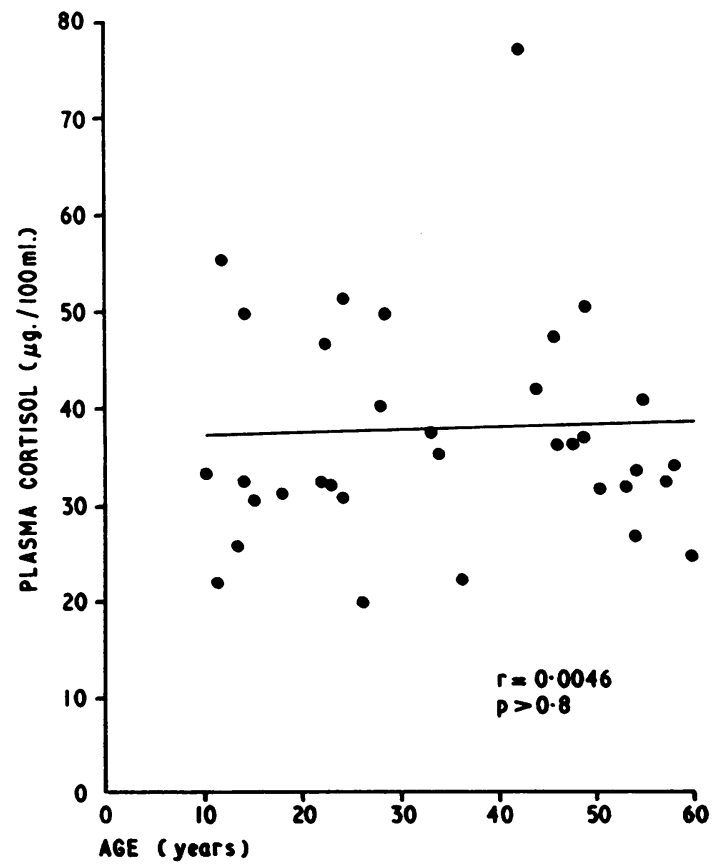

FIG. 3. Eight-hour plasma cortisol levels compared with age. 
in a few instances, plasma steroids. The results have been conflicting.

Rackemann (1945) estimated the urinary 17-ketosteroids (17-KS) in an asthmatic patient and found low values: this finding was described by other workers (Eriksson-Lihr, Forssell, Pettay, and Rusk, 1949 ; Israels, Dingemanse, Huis In't Veld, and Orie, 1953; Lemon, Kravetz, Michelson, Lowell, and Wotiz, 1958). On the other hand, Mustafá, Jiménez Díaz, and Vivanco (1960), in a study of 27 asthmatic patients, found normal urinary 17-KS levels in 22 patients and slightly subnormal values in five patients; they also estimated urinary 17 -hydroxycorticosteroids (17-OHCS), which were normal in every case. Davies (1956), in a study of 38 asthmatics, found normal values of urinary 17-KS and 17-ketogenic steroids (17-KGS); Kass and Appleby (1960) could find no difference between the urinary 17$\mathrm{KS}$ and 17-OHCS in asthmatic and non-asthmatic patients before and after stimulation with an A.C.T.H. infusion.

Several studies on plasma steroids in asthma have been published, but again there is no general agreement on the results. For instance, Siegel, Ely, Birnberg, and Kelley (1956) estimated plasma 17-OHCS in 57 asthmatics and found high levels in 'severe' and 'moderate' asthma, but normal levels in 'mild' and 'asymptomatic' cases. On the other hand, Vaccarezza (1961) determined plasma 17-OHCS before and after intramuscular A.C.T.H. in 22 cases of 'allergic' asthma and found high plasma 17-OHCS with a diminished response to A.C.T.H.

In the present series, urinary steroid metabolites (17-KS, 17-OHCS and/or 17-KGS) were assayed in 18 patients. The results fell within or a little below the normal range, and no firm conclusions can be drawn from them. Therefore they add little to the conflicting evidence already published. However, here we have used techniques which measure cortisol itself, thus avoiding the inaccuracies and difficulties of interpretation inherent in less specific methods.

The results obtained from the estimation of the cortisol production rate indicate that there was no depression of adrenocortical function when the subjects were resting and their asthma was quiescent. However, when the adrenal cortex was stimulated by A.C.T.H., 23 of 34 subjects ( $68 \%$ ) were unable to respond normally, and of the remaining 11 subjects, five were in the low normal range.

The cause of this diminished response to stimulation remains obscure, but a clue is provided by the inverse relationship between the duration of symptoms and the adrenal response to A.C.T.H. That is, the longer a patient has had asthma the more likely he is to have diminished adrenocortical reserve. For instance, of 15 patients who had had asthma for less than 10 years, seven had a normal response, whereas of 19 patients whose disease had been present for 10 years or more, only four had a normal response. On the other hand, the two patients whose disease had been present for less than a year had a diminished response.

The reason for these findings is a matter of speculation, but either individuals who develop continuous asthma are more liable to have a diminished adrenocortical reserve, or the reduced reserve is a consequence of the disease. It is possible that the reduction in adrenocortical reserve is not the primary abnormality but is secondary to an abnormality of corticotrophin production by the anterior pituitary. Further studies are being carried out on the asthmatic subjects after a prolonged course of corticotrophin and corticosteroid treatment.

From the present study it is not apparent whether these patients would be better treated with adrenocorticosteroid drugs or corticotrophin, but one practical point emerges. It is often held that adrenocortical steroids should be reserved for treating acute attacks and should only be used on a long-term basis in the most intractable cases. One of the reasons given for this view is the prevention of adrenocortical depression. In the majority of our patients such a depression existed without previous steroid therapy. This finding may be an additional justification for regular maintenance treatment in patients with continuous asthma whose capacity for work and normal living is impaired, more particularly in those with a long history.

\section{SUMMARY}

The adrenal function in 34 patients with continuous asthma has been assessed by measuring plasma cortisol before and during A.C.T.H. stimulation and, in 21 patients, by estimating resting cortisol production rates.

No patient had previously received corticosteroid or corticotrophin therapy at any time.

The resting cortisol production rates fell within normal limits.

Twenty-three patients had a diminished response to A.C.T.H. stimulation and 11 patients had a normal response. Thus there is evidence that in the majority of these patients the adrenal cortex was not functionally normal. 
There is a significant correlation between duration of symptoms and a diminished response to A.C.T.H. stimulation.

We wish to express our thanks to Professor A. L. Latner and Dr. A. G. Ogilvie for their constant help and encouragement, and to Dr. Ogilvie for allowing us to study patients under his care. We are grateful to Dr. D. Newell for statistical advice.

One of us (J. R. K.) was in receipt of a grant from the Board of Governors, United Newcastle upon Tyne Hospitals.

We are indebted to Organon Laboratories for a supply of Cortrophin and to the United States National Institutes of Health, Bethesda, for a supply of cortisol- $4-{ }^{14} \mathrm{C}$ to Professor Latner.

\section{REFERENCES}

Cameron, E. A., and Kilborn, J. R. (1964). Plasma cortisol and corticosterone response to infused corticotrophin in normal subjects. Clin. chim. Acta, $10,308$.

Ciba Guest Symposium (1959). Terminology, definitions, and classification of chronic pulmonary emphysema and related conditions. Thorax, 14, 286.

Cope, C. L. and Black, E. G. (1958). The behaviour of 14c-cortisol and estimation of cortisol production rate in man. Clin. Sci., $17,147$.

Davies, B. M. (1956). Adreno cortical function in severe asthma. Acta Allerg. (Kbh.), 10, 1.

Eik-Nes, K., Sandberg, A. A., Nelson, D. H., Tyler, F. H., and Samuels, L. T. (1954). Changes in plasma levels of 17-hydroxycorticosteroids during the intravenous administration of ACTH. I.A. test of adrenocortical capacity in the human. J. clin. Invest. 33, 1502 .
Engström, I., Escardo, F. E., Karlberg, P., and Kraepelin, S. (1959). Respiratory studies in children. VI. Timed vital capacity in healthy children and in symptom-free asthmatic children. Acta paediat. (Uppsala), 48, 114.

Eriksson-Lihr, Z., Forssell, P., Pettay, O., and Rusk, I. (1949). Investigation of the function of the suprarenal cortex in allergic diseases. Acta allerg. (Kbh.), $2,299$.

Israels, A. A Dingemanse, E., Huis In't Veld, L. G, and Orie N. G. M. (1953). The excretion of neutral 17-ketosteroids of adrenal and gonadal origin in bronchial asthma with and without a bacterial bronchitis. Ibid., 6, Suppl. 3, p. 55 .

Kass, I., and Appleby, S. (1960). The status of the adrenal gland in the asthmatic patient. Amer. J. med. Sci., 240, 213.

Lemon, H. M., Kravetz, P., Michelson, A. L., Lowell, F. C., and Wotiz, H. H. (1958). Endocrine function in bronchial asthma and hay fever. $J$. Allergy, 29, 384.

Mattingly, D. (1963). Plasma steroid levels as a measure of adrenocortical activity. Proc. roy. Soc. Med., 56, 717.

de Moor, P., de Backer, W., Hendrikx, A., Hinnekens, M., and de Bock, A. (1960). Analysis by means of an analog computer of plasma corticoid values during adrenocorticotrophic hormone infusion. J. clin. Invest., 39, 816 .

Mustafá, O. S., Jiménez Diaz, C., and Vivanco, F. (1960). The state of the adrenocortical function in bronchial asthma. Bull. Inst. med. Res. (Madr.) 13, 25.

Ogilvie, A. G. (1962). Asthma: A study in prognosis of 1,000 patients. Thorax, i7, 183 .

Rackemann, F.M. (1945). Depletion in asthma. J. Allergy, 16, 136. (1958). Asthma is a constitutional disease. Ibid., 29, 535 .

and Edwards, M. C. (1952). Asthma in children. A follow-up study of 688 patients after an interval of twenty years. New Engl. J. Med., 246, 815.

Scadding, J. G. (1963). Meaning of diagnostic terms in bronchopulmonary disease. Brit. med. J., 2, 1425.

Siegel, S. C., Ely, R. S., Birnberg, V., and Kelley, V. C. (1956). Adrenal function in allergy. 1. Plasma 17-hydroxycorticosteroid concentrations in children with bronchial asthma.J. Allergy, $27,504$.

Stewart, C. P., Albert-Recht, F., and Osman, L. M. (1961). The simultaneous fluorimetric microdetermination of cortisol and carticosterone in plasma. Clin. chim. Acta, 6, 696.

Strang, L. B. (1961). M.D. Thesis, Univ. of Durham.

Vaccarezza, J. R. (1961). The suprarenal function in allergic asthma Dis. Chest, 40,121 .

De Witt, G. F., Robson, J. S., and Stewart, C. P. (1962). Studies of hydrocortisone production as measured by isotope dilution techniques in adrenocortical diseases and in idiopathic hirsutism. Clin. chim. Acta, 7, 664 . 